\title{
Android Based Personal Finance Management Application: Design and Development
}

\author{
Brilly Andro Makalew \\ Mobile Application \& Technology Program, School of Computer Science, \\ Bina Nusantara University, \\ Jakarta, Indonesia 11480 \\ bmakalew@binus.edu
}

*Correspondence: bmakalew@binus.edu

\begin{abstract}
The aim of this work is to design an application with the main function to ease the user in the process of managing their personal finance. The process of evaluating their financial activities record should becomes easier because the application enables their own financial goal to be monitored, controlled, and evaluated using the data. There are two phases in this research: (1) concept evaluation phase, and (2) content realization phase. The first phase produced a list of approved features that had undergone a series of concept testing. All features support all three time period: past, present, and future. Users can see their past activities, record their present transaction, and plan their future goals. The second phase produced a design for a mobile application, specifically in a form of use case diagram and class diagram. Feature comparison between similar applications had also been done twice, in the beginning and at the end. All process are done to ensure that the concept are designed as objective as possible.
\end{abstract}

Keywords: Personal finance management; mobile application; software design.

\section{INTRODUCTION}

In current globalization era, quality of good and service keeps on increasing. This is caused by the intention of every organization to individual to fight and survive in an ever-expanding and crowded market. This results in a variety of ways used by each sales and marketing team to inject their product image in the eyes and minds of the consumers to shorten their time to consider about product importance, and will reduce their awareness of current personal financial statement. A long-term thinking is required to disillusionize consumers on their purchase.
According to Bruce Hokin (Hokin, 2018), the main issue personal finance is spending without knowing their limits and spending without target. A lot of people find their income is considerably small, and it causes inability to save for bigger and better things in the future. In a basic principle, that kind of feeling can be prevented as long as expenditure ratio is adjusted with income ration. When someone has determined and managed their own personal finance, specified their purpose, and have a supporting tool to integrate all of those matters, the issue should be solved, and the people can be more well organized in financial matter (Rutledge \& Deshpande, 2014). A well-organized personal finance can lead to happiness and improvement in well being happiness and well being (Ivonin, Perry, \& Subramanian, 2016), improve work performance in workplace (Fernando, 2016), improve achievement for students (Hill \& Asarta, 2016), and of course directly associated with saving rates (Peng et.al, 2007) . This shows that inability in managing personal finance is really important.

The optimal tool to assist with mentioned problems should not cause more problems. The assistance must also be done in a correct manner of approach. It was proven that the simpler the personal finance assistance is to use, the more effective effect and output it produces (Drexler, Fischer, \& Schoar, 2014).

In the current digitalized word, one most optimum tool should also be injected with technology in the term of effectiveness and efficiency. Considering a mobility in purchasing goods or services, a mobile application is determined as the most optimal information technology to be used, more specifically a smartphone. A more optimum smartphone to be used is Android based smartphone, considering it's has the biggest market share in Indonesia (Statcounter, 2018). 
Upon considering the benefit and value of smartphone as a tool to support personal finance management, this research is expected to address the gap by utilizing smartphone to solve personal finance related issues. Although not widely used, personal finance application when used right (or not right) can be pervasive in the users' financial life (Lewis \& Perry, 2019).

\subsection{Aim \& Limitation}

This work is aimed to establish and present a prototype for mobile application intended to manage personal finance, especially in three main aspect: budgeting, needs organizing, and goal setting. Because of the big scope of personal finance, this work will not cover external behaviour, for example automatic payment for credit card bills. The purpose of this work is to provide a depiction of an optimum personal finance mobile application, along with proposed feature, and is aimed to enable a more effective financial management, more specifically for Indonesian users.

A personal financial management is a process of planning an individual to achieve personal economic satisfaction (Hughes, Dlabay, \& Hughes, 1994). This planning process is aimed to help people to control their financial situation. Every person has different financial conditions and needs; therefor financial planning must be done well and correctly. This should lead to a fulfilment on a specific goal or necessity. A comprehensive financial management may increase a person's well-being, along with improving personal satisfaction by reducing uncertainty in needs and goal in the future.

By doing a good financial planning, individuals are able to obtain a lot of advantages, one of those being the opportunity to obtain, use, and protect their personal financial more effectively. This is caused by the concept of realizing their own current financial condition, enabling them to be wiser in managing their finance. This wise management should enable them to be spared from overspending, debt, or dependency from other entity, due to their financial freedom. Another benefit is to be free from worry caused by the benefit of estimation ability.

\subsection{Financial Planning Process}

Financial planning is an ever going process, and the status can change according to situational change in life, coming from personal or family wise (Keown, 2013). There are 5 basic steps in dong personal financial management: (1) evaluating financial health, (2) determining financial goal, (3) establishing plan, (4) implementing plan, and (5) revisit, re-evaluate, and revise plan.

\subsection{Type of expenses}

Personal expenses can be classified into 2 types: (1) fixed expenses, and (2) variable expenses (Pant, 2018). Fixed expense is a type of expenses that describe reoccurring spending, usually in a monthly timeframe. Some of the examples are house instalments and insurances. This type of expenses is not easy to modify. For example, to reduce house instalment, a homeowner must be able to find another house with a lower price, which is neither an easy nor a fast process to do. Reducing this type of expenses has a huge impact on one's life, because of the heavy factor it brings: commitment.

Another type of expenses is variable expense. A variable expense is a type of expenses that has a nonconsistent timeline, and can vary every month. Discretionary expenses are often belong in this type of expenses, meaning that it vary depending on the owner's decision. Although vary, the expenses that is classified in this category may also reoccur every month, for example electricity, water, and gas bills. When people are trying to save, this is the type of expense that is often minimized.

\section{METHODS}

The methodology in specifically chosen to incorporate software development. Unified Modelling Language (UML) based diagrams were used. Although there are a lot of diagrams to use in the process of implementing UML, we used Use Case Diagram and Class Diagram to represent the model for this application. The conceptual framework for this work is visible in Figure 1.

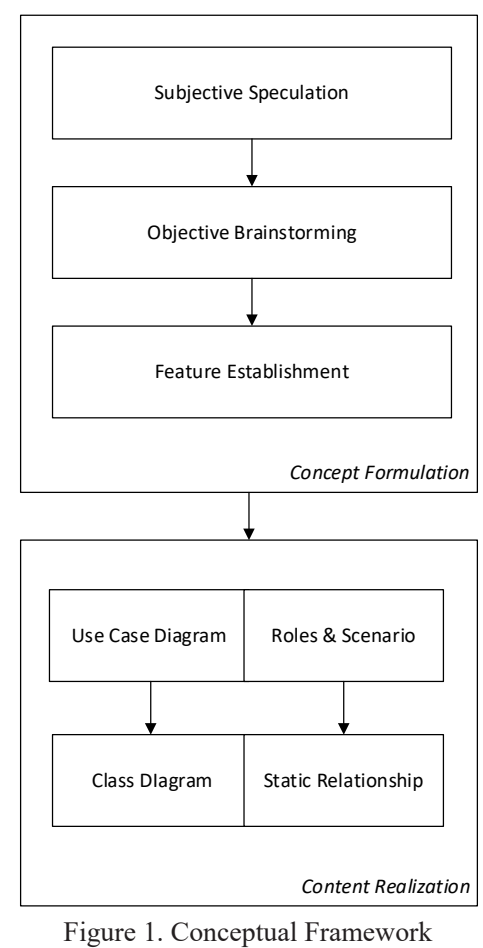

There are 2 phases in this methodology, first is the concept formulation. Concept formulation phase is done to provide a list of requirement and feature to be realized into an application design. The second phase, Content Realization phase, is a phase of realizing all feature list and specification produced from the first phase. The final output of this research is an application design to be followed up by technical development.

\subsection{Concept Formulation Phase}

\subsubsection{Subjective Speculation}

The first activity of the concept formulation phase is to bring individual suggestion on what the application should look like. We speculate on what type of solution 
will be able to solve the problems, and how it would look like. The main purpose of this activity is to establish an individual concept that can be discussed and test later after moving to the next activity.

\subsubsection{Objective Brainstorming}

Following the first activity is the objective brainstorming activity. This is where all concept that had been discussed were challenged from all angle, starting from the feasibility, complexity, scalability, and suitability to the core goal. All member are required to present their idea of features along with relevant data, for example previous research, similar application, proof of market demand, and more importantly, customer segmentation. The output of this activity is a few selected features that had successfully passed all the conceptual testing stage.

\subsubsection{Feature Establishment}

The last activity in this phase is the establishment of features that is going to be developed. All selected freatures from the previous phase were challenged for one more time to find the winning feature, and to finally document the process and prepare it to move on to the next phase.

\subsection{Content Realization Process}

\subsubsection{Use Case Diagram}

Use Case Diagram and Class Diagram were chosen because they complement each other in term of describing a system static behavior. Use Case Diagram is deemed suitable because of its ability to represent relationships between entities. Two entities were identified in this system, which are (1) user, and (2) system.

\subsubsection{Class Diagram}

When designing an Object-Oriented system, Class Diagram is one of the necessities to utilize. The main purpose of this diagram is to enable the identification and depiction of dynamic workflow between all entities. In this work, Class Diagram is used alongside Use Case Diagram to further emphasize on the interaction, because although the concept and purpose of this application is not too complex, the complexity of interaction between entities inside the system is considered high.

\section{RESULTS AND DISCUSSION}

After doing a thoroughly methodical process, this work has produce two kind of output: (1) feature list as a product of Concept Formulation phase, and (2) use case diagram and class diagram as a product of Content Realization phase.

\subsection{Concept Formulation Result}

There are a total of 9 features that emit as a result and output from the first phase, Concept Formulation. At first, there are a total of 30 proposed features. After continuing to the next activity, 11 features remained, and 19 features were eliminated due to being too similar, or did not pass the feasibility, complexity, scalability, and suitability test. Finally upon further discussion, 9 features were determined to be the main features in this application. The detail of each features are described in Table 1.

Table 1. Feature List

\begin{tabular}{|c|c|}
\hline Feature & Description \\
\hline Getting Started & $\begin{array}{l}\text { This is a feature used to familiarize } \\
\text { user to the application. This feature } \\
\text { consists of explanation and tutorial on } \\
\text { how to use the application }\end{array}$ \\
\hline $\begin{array}{l}\text { Details for Every } \\
\text { Function }\end{array}$ & $\begin{array}{l}\text { This feature enables user to see the } \\
\text { detail for every function, feature, and } \\
\text { page. The main purpose is to guide } \\
\text { users to optimize the application } \\
\text { usability }\end{array}$ \\
\hline Goal Setting & $\begin{array}{l}\text { This is used to creat a financial goal, } \\
\text { for example to buy a car, or to buy a } \\
\text { new house. By finding and writing } \\
\text { down their goal, users can create a } \\
\text { more directed plan by putting their } \\
\text { remaining balance, their saving needs, } \\
\text { and also enabling them to make a } \\
\text { suitable financial planning. }\end{array}$ \\
\hline Budgeting & $\begin{array}{l}\text { This feature enables user to register } \\
\text { their budget for every type of } \\
\text { expenses. On using this feature, the } \\
\text { limit for every expense type becomes } \\
\text { clearer. User can also make expenses } \\
\text { budget, and to not exceed determined } \\
\text { limit. }\end{array}$ \\
\hline Organize Needs & $\begin{array}{l}\text { With this, users can record their plan, } \\
\text { especially on their planning their } \\
\text { needs according to set budget per } \\
\text { determined expense type. }\end{array}$ \\
\hline Type of Expense & $\begin{array}{l}\text { Users can categorize their expenses } \\
\text { into } 3 \text { main category to know more } \\
\text { about how they are spending. The } \\
\text { main categories are fixed, variable, } \\
\text { and optional expenses. Fixed expenses } \\
\text { are recurring expenses with the same } \\
\text { amout every month. Variable expenses } \\
\text { are recurring, but has different amount } \\
\text { every month. Optional expenses are } \\
\text { some expenses they don't really need, } \\
\text { and can only be used after they have } \\
\text { enough income for both fixed and } \\
\text { variable expenses }\end{array}$ \\
\hline
\end{tabular}

Indicator for This is a feature to give visual Budgeting awareness to users. This features inform the user when they are nearing budget, or when they pass it. It will show red color when exceeding budget, and yellow budget when they have reached $10 \%$ of the budget. The process of deciding on $10 \%$ is arbitrary

Transaction This is a log function, meaning it only History has one specific function, which is to record any activity done by user. This is used to provide historical data that can be used to evaluate past activity, or to plan future activity.

Reminder This is used to remind user about when they have to pay bills, or what they have to do, and everything else related to their personal finance management.

After the feature has been determined, firstly we compare it to the previously analyzed applications to further establish the state of the art and the novelty of this work. The comparison result is visible in Table. 
Table 2. Comparison - New App vs Previous Apps

\begin{tabular}{clcccc}
\hline No. & \multicolumn{1}{c}{ Feature } & $\begin{array}{c}\text { My } \\
\text { Budget } \\
\text { Book }\end{array}$ & $\begin{array}{c}\text { Easy } \\
\text { Money }\end{array}$ & $\begin{array}{c}\text { Mone } \\
\text { Wise }\end{array}$ & $\begin{array}{c}\text { New } \\
\text { App }\end{array}$ \\
\hline 1 & Getting Started & $\sqrt{ }$ & $\sqrt{ }$ & $\sqrt{ }$ & $\sqrt{ }$ \\
\hline 2 & $\begin{array}{l}\text { Details } \\
\text { for Every } \\
\text { Function }\end{array}$ & - & - & - & $\sqrt{ }$ \\
\hline 3 & Goal Setting & - & - & - & $\sqrt{ }$ \\
\hline 4 & Budgeting & $\sqrt{ }$ & $\sqrt{ }$ & $\sqrt{ }$ & $\sqrt{ }$ \\
\hline 5 & $\begin{array}{l}\text { Organize } \\
\text { Needs }\end{array}$ & - & - & - & $\sqrt{ }$ \\
\hline 6 & $\begin{array}{l}\text { Type of } \\
\text { Expense }\end{array}$ & - & - & - & $\sqrt{ }$ \\
\hline 7 & $\begin{array}{l}\text { Indicator for } \\
\text { Budgeting }\end{array}$ & $\sqrt{ }$ & $\sqrt{ }$ & $\sqrt{ }$ & $\sqrt{ }$ \\
\hline 8 & $\begin{array}{l}\text { Transaction } \\
\text { History }\end{array}$ & $\sqrt{ }$ & $\sqrt{ }$ & $\sqrt{ }$ & $\sqrt{ }$ \\
\hline 9 & Reminder & - & $\sqrt{ }$ & - & $\sqrt{ }$ \\
\hline & & & & & \\
\hline
\end{tabular}

\subsection{Content Realization Result}

Content realization produced two main output, which are Use Case Diagram, and Class Diagram. Each diagram can be seen in Figure and Figure respectively.

\subsection{Use Case Diagram}

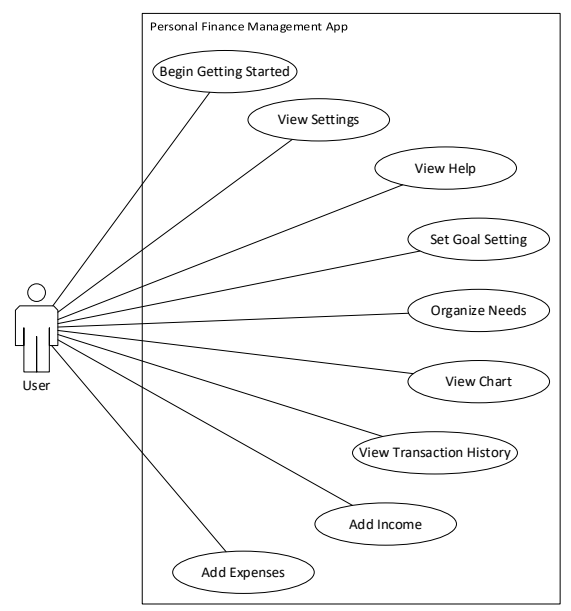

Figure 2. Use Case Diagram

3.4 Class Diagram

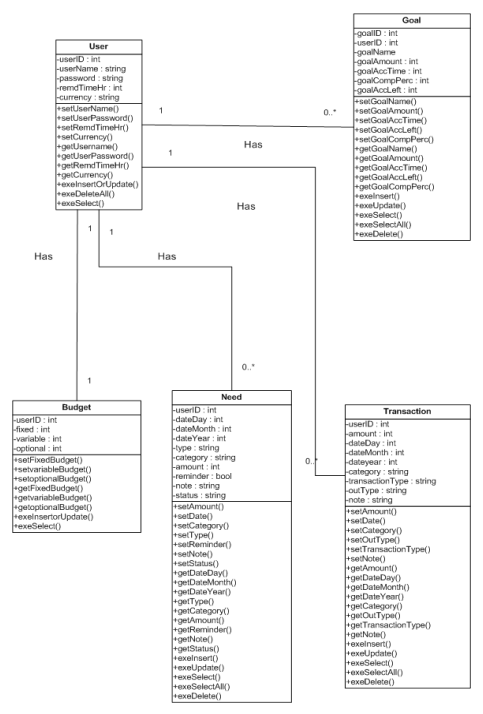

Figure 3. Class Diagram

\subsection{UI Design}

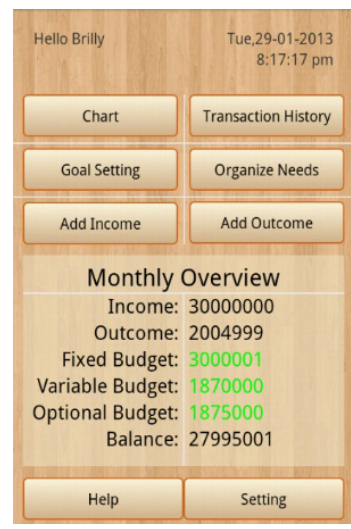

Figure 4. Homepage

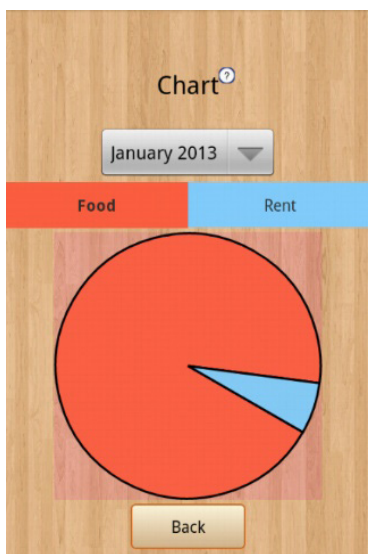

Figure 5. Chart Page

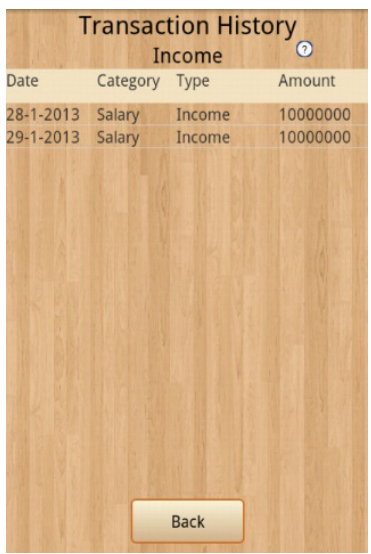

Figure 6. History Page

\section{CONCLUSION}

Our new application provide novelty features compared to other similar applications. These features are expected to fulfil the needs of every user, especially the ones about personal financial management. This application also provides complete and accurate notes about users' financial activity, and this is expected to ease user in their financial evaluation process. This application also enables an easy depiction of their financial statement every month. A calculation of total income and expenses per month, balance, and budgeting indicators inside the applications are expected to provide clear description on the users' financial statement. This financial application also enables 
user to register their financial activity. Due to the basis of the application being mobile application, the registration of their activity can be done anywhere and anytime, as long as they bring their smartphone. When users want to make financial planning, they can easily do it using pre-defined steps in the application. Finally, the application can help users to remember about their bills or other financialrelated-activities using the reminder system. This will save a lot of time and money, especially if late payment results in financial fine.

\section{REFERENCES}

Drexler, A., Fischer, G., \& Schoar, A. (2014). Keeping it simple: Financial literacy and rules of thumb. American Economic Journal: Applied Economics , 6 (2), 1-31.

Fernando, S. D. (2016). Employee Personal Financial Literacy as Strategic Human Resource Management Initiative: With special reference to ABC Bank PLC. 7th International Conference on Business \& Information ICBI - 2016, Faculty of Commerce and Management Studies (p. 9). University of Kelaniya.

Hill, A. T., \& Asarta, C. J. (2016). Gender and Student Achievement in Personal Finance: Evidence from Keys to Financial Success. International Handbook of Financial Literacy.

Hokin, B. (2018). Personal Finance Problems. Retrieved 2018 from Streetdirectory: https://www.streetdirectory.com/travel_guide/166363/finance/personal finance problems.html

Hughes, R. J., Dlabay, R. L., \& Hughes, R. J. (1994). Personal Finance (Vol. VII). Irwin: McGraw Hill.

Ivonin, L., Perry, M., \& Subramanian, S. (2016). The art of spending and recommendations in personal finance. CEUR Workshop Proceedings.

Keown, A. J. (2013). Personal Finance. Pearson.

Lewis, M., \& Perry, M. (2019). Follow the money: Managing personal finance digitally. In Proceedings of the 2019 CHI Conference on Human Factors in Computing Systems (pp. 1-14).

Pant, P. (2018). What's the Difference Between Fixed \& Variable Expenses. Retrieved 2018 from The Balance: https://www.thebalance.com/what-sthe-difference-between-fixed-and-variable-expenses- 453774

Peng, T. C. M., Bartholomae, S., Fox, J. J., \& Cravener, G. (2007). The impact of personal finance education delivered in high school and college courses. Journal of family and economic issues, 28(2), 265-284.

Rutledge, D., \& Deshpande, S. (2014). The Influence of Time Orientation on Personal Finance Behaviours. Ideas in Marketing: Finding the New and Polishing the Old.

Statcounter, G. (2018). Mobile Operating System Market Share Indonesia . Retrieved 2018 from Global Statcounter: http://gs.statcounter.com/os-market-share/mobile/indonesia 